\title{
Short-term efficacy of 1-month and 3-month gonadotropin-releasing hormone agonist depots in girls with central precocious puberty
}

\author{
Min Jin Jeon', \\ Jae Won $\mathrm{Choe}^{2}$, \\ Hye Rim Chung ${ }^{2}$, \\ Jae Hyun $\mathrm{Kim}^{2,3}$
}

${ }^{1}$ Department of Pediatrics, Seoul National University Children's Hospital, Seoul, Korea

${ }^{2}$ Department of Pediatrics, Seoul National University Bundang Hospital, Seongnam, Korea

${ }^{3}$ Department of Pediatrics, Seoul National University College of Medicine, Seoul, Korea
Received: 27 June, 2020

Revised: 8 December, 2020

Accepted: 27 April, 2021

\section{Address for correspondence:}

Jae Hyun Kim

Department of Pediatrics, Seoul National University Bundang Hospital, 82, Gumi-ro 173 Beongil, Bundang-gu, Seongnam 13620, Korea

Email: pedendo@snubh.org https://orcid.org/0000-0002-02037443
Purpose: Gonadotropin-releasing hormone agonist ( $\mathrm{GnRHa}$ ) has been the mainstay of central precocious puberty (CPP) treatment for decades, but few reports have compared the efficacy of 1-month and 3-month depot GnRHa formulations. This study investigates the short-term efficacy of 1-month and 3-month GnRHa depots in girls with CPP.

Methods: Overall, 150 girls with CPP were included in a retrospective review of medical records. Subjects in group $1(n=105)$ were treated with 1-month $\mathrm{GnRHa}$ depots for $\geq 12$ months, and those in group $2(n=45)$ were treated with 1-month GnRHa depots for 6 months followed by 3-month GnRHa depots for $\geq 6$ months. Anthropometric and biochemical data were compared between the groups at 3-time points (after 0,6 , and 12 months of GnRHa treatment).

Results: Demographic and clinical characteristics did not differ between the groups at baseline or after 6 months of GnRHa treatment. After 12 months of $\mathrm{GnRHa}$ treatment, patients in the both groups showed no difference in bone age (BA), chronological age (CA), BA-CA difference, height standard deviation score (SDS) for $C A$ and $B A$, or body mass index SDS for CA and BA. The sexual maturity rate of the breast was prepubertal at 12 months in most of subjects. GnRH-stimulated luteinizing hormone (LH) level was suppressed during GnRHa treatment in both groups at 6 and 12 months, although the LH level in group 2 was higher than that in group 1.

Conclusion: Treating CPP with a 3-month GnRHa depot showed short-term efficacy comparable to that with a 1-month depot in anthropometric parameters and pubertal suppression.

Keywords: Precocious puberty, Gonadotropin-releasing hormone agonist, Treatment outcome, Girls

\section{Highlights}

- In Korea, 1-, 3-, and 6-month depot formulations of GnRHa have been approved for treatment of CPP.

- Treatment with a 3-month GnRHa depot in CPP girls was comparable to that with a 1-month depot in many clinical aspects.

- A 3-month depot formulation of GnRHa could be a viable option for treatment of CPP.

\section{Introduction}

Central precocious puberty $(\mathrm{CPP})$ in girls is defined as the onset of breast development before 8 years of age as a result of premature activation of the hypothalamic-pituitary-gonadal 
axis. ${ }^{1,2)}$ Early menarche can cause short adult stature because of early epiphyseal closure and emotional, behavior, and mood fluctuations because of physical differences from peers with normal puberty. ${ }^{2,3)}$ To prevent the adverse outcomes of CPP, early diagnosis and appropriate treatment are essential. After biochemical confirmation of CPP using gonadotropin-releasing hormone $(\mathrm{GnRH})$ stimulation tests in patients with early signs of puberty, a depot formulation of a GnRH agonist (GnRHa) is used as standard therapy. ${ }^{4)}$

Because continuous GnRH secretion, rather than intermittent exposure to it, suppresses pubertal development by desensitizing and downregulating pituitary GnRH receptors, GnRHa is used to treat $\mathrm{CPP}^{5}{ }^{5}$ Several previous studies have reported that GnRHa treatment in CPP regresses pubertal symptoms and signs and increases predicted adult height $(\mathrm{PAH}){ }^{2,5-7)}$ In Korea, several doses of depot formulations of GnRHa, leuprolide (3.75 $\mathrm{mg}$ and $11.25 \mathrm{mg}$ ), and triptorelin $(3.75 \mathrm{mg}, 11.25 \mathrm{mg}$, and $22.5 \mathrm{mg}$ ) have been approved for treatment of CPP. The most commonly used GnRHa formulation is a 1-month depot.

Previous reports have demonstrated that treating CPP with a 3-month formulation can suppress pubertal development more efficiently than can a 1-month formulation. ${ }^{8-10)}$ Treatment with a 3 -month preparation could reduce the burden of injections and improve convenience and compliance. ${ }^{11)}$ However, few reports have evaluated the effects of switching medication from the 1-month to the 3-month formulation. ${ }^{8}$ Additionally, no clinical information is available about 3-month GnRHa treatment in Korean CPP patients. Therefore, this study compares the short-term efficacy in terms of anthropometric and laboratory parameters of a 3-month GnRHa depot with that of a 1-month depot in girls diagnosed with CPP.

\section{Materials and methods}

\section{Subjects}

Girls diagnosed with CPP at the Pediatric Endocrinology Clinic of Seoul National University Bundang Hospital from January 2016 to December 2018, were considered as potential candidates for this study. The inclusion criteria were as follows: (1) breast development before the age of 8 years, (2) advancement of bone age (BA) over chronological age (CA), (3) peak luteinizing hormone (LH) level $\geq 5 \mathrm{IU} / \mathrm{L}$ in the GnRH stimulation test, (4) start of GnRHa treatment at the age of 7.0-8.9 years, and (5) GnRHa treatment using a 1-month depot formulation for $\geq 12$ months or a 1-month depot formulation for 6 months followed by a 3-month depot formulation for $\geq 6$ months. Among the 264 subjects who met the inclusion criteria, 150 girls with CPP were included in this study after exclusion of subjects with (1) CPP caused by organic brain lesions such as brain tumors or anomalies $(n=11)$; (2) endocrinological disorders such as hypothyroidism, hyperthyroidism, or adrenal disease ( $\mathrm{n}=13$ ); (3) chronic illness such as diabetes mellitus or inflammatory disorders $(\mathrm{n}=30)$; or (4) a history of recombinant human growth hormone treatment $(\mathrm{n}=60)$.

\section{Methods}

Data were obtained from a retrospective review of medical records. The following demographic and anthropometric data were collected before treatment and after 6 months and 12 months of GnRHa treatment: CA, BA, height, weight, body mass index (BMI), sexual maturity rating (SMR), midparental height, and birth weight. Height was measured using a Harpenden Stadiometer (Holtain Ltd., Crosswell, UK), and weight was measured using an electric balance (GL-310; G-Tech International Co. Ltd., Seoul, Korea). BMI was calculated as weight in kilograms divided by height in meters squared. Height and BMI were transformed into standard deviation score (SDS) for the corresponding CA and BA using the 2017 Korean National Growth Charts. ${ }^{12}$ BA from plain radiographs of the left hand was interpreted by a single pediatric endocrinologist using the Greulich-Pyle method. ${ }^{13)}$ SMR was assessed using the Marshall and Tanner method. ${ }^{14)}$ PAH was calculated according to the Bayley-Pinneau method. ${ }^{15)}$

For diagnosis of CPP, all subjects underwent GnRH stimulation tests using an intravenous injection of $0.1 \mathrm{mg}$ of synthetic GnRH (Relefact; Sanofi-Aventis, Frankfurt, Germany). Blood samples were obtained before and at 15, 30, 45, and 60 minutes after GnRH injection to measure LH, follicle-stimulating hormone (FSH), and estradiol. Basal and peak levels of LH and FSH and basal estradiol level were used for the analysis. $\mathrm{LH}$ and FSH levels were measured using immunoradiometric assays, and estradiol level was measured via radioimmunoassay (DIAsource, Ottignies-Louvain-la-Neuve, Belgium).

Study subjects were divided into 2 groups according to mode of GnRHa administration (Fig. 1). Group $1(\mathrm{n}=105)$ comprised subjects treated with a 1-month depot formulation of GnRHa (leuprolide acetate; Leuplin depot $3.75 \mathrm{mg}$, Takeda, Tokyo, Japan) every 4 weeks for at least 1 year. Group $2(n=45)$ comprised subjects treated with a 1-month depot formulation of GnRHa (leuprolide acetate; Leuplin depot $3.75 \mathrm{mg}$, Takeda) every 4 weeks for the first 6 months of treatment and then with a 3-month depot formulation (leuprolide acetate; Leuplin DPS depot $11.25 \mathrm{mg}$, Takeda) administered every 3 months for at least 6 months. Initially, $60-90 \mu \mathrm{g} / \mathrm{kg}$ of leuprolide acetate was

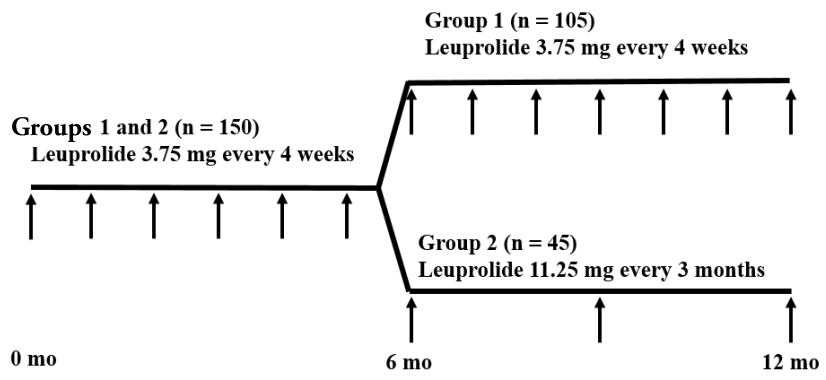

Fig. 1. Scheme of the present study. 
administered subcutaneously every 4 weeks for all subjects. In group 2, the dose of the 3-month depot formulation was 3 times the last dose of the 1-month depot formulation. The dose of each formulation was adjusted according to growth rate and SMR. Every 6 months, the LH level was measured 30 minutes after administration of synthetic GnRH. Stimulated LH level less than 3 IU/L indicated sufficient pubertal suppression. ${ }^{16)}$

\section{Statistical analyses}

Data analysis was performed using Stata 16.1 (StataCorp LP, College Station, TX, USA). Data are presented as mean \pm standard deviation for continuous variables and as number and percentage of subjects for categorical variables. Student $t$-test and Fisher exact test were used to compare groups 1 and 2. For comparison of continuous or categorical variables obtained at 3-time points in each group, repeated measures analysis of variance or Fisher exact test was used, respectively. A $P$-value less than 0.05 was considered statistically significant.

\section{Results}

\section{Baseline characteristics of the study subjects}

The baseline characteristics of the 150 patients enrolled in this study are presented in Table 1. The mean CA and BA and the difference between BA and CA were $8.4 \pm 0.6$ years, $10.0 \pm 0.7$ years, and $1.6 \pm 0.7$ years, respectively, which revealed no difference between groups (all $P>0.05$ ). Furthermore, there were no significant differences in height SDS for CA and BA, BMI SDS for CA and BA, or PAH. Although breast SMR was higher in group 2 than in group $1(P<0.001)$, there was no difference between basal or peak LH and FSH levels or basal estradiol level between the 2 groups. The GnRHa dose in group 2 was significantly higher than that in group $1(84.9 \pm 9.0 \mu \mathrm{g} / \mathrm{kg} / \mathrm{mo}$ vs. $78.4 \pm 9.3 \mu \mathrm{g} / \mathrm{kg} / \mathrm{mo}, P<0.001)$.

\section{Changes in clinical parameters during GnRHa treatment}

During treatment, subjects in both groups showed significant decrease in BA-CA difference and height SDS for CA and significant increase in height SDS for BA, BMI SDS for CA and $\mathrm{BA}$, and PAH (Table 2, Fig. 2). Breast SMR regressed significantly in both groups. Among the participants, $6.7 \%$ after 6 months and $4.7 \%$ after 12 months of GnRHa treatment showed a breast SMR of 2, but the difference between the groups was not significant. LH level after GnRH stimulation was suppressed at 6 months and sustained at 12 months in both groups $(1.1 \pm 0.5$ $\mathrm{IU} / \mathrm{L}$ at 6 months and $1.1 \pm 0.4 \mathrm{IU} / \mathrm{L}$ at 12 months in group 1 and $1.2 \pm 1.0 \mathrm{IU} / \mathrm{L}$ at 6 months and $1.4 \pm 0.5 \mathrm{IU} / \mathrm{L}$ at 12 months in group 2). At 6 months, 2 patients in group 2 were not suppressed

Table 1. Baseline demographic and clinical characteristics of study subjects

\begin{tabular}{|c|c|c|c|c|}
\hline Variable & Total $(n=150,100 \%)$ & Group $1(n=105,70 \%)$ & Group $2(n=45,30 \%)$ & $P$-value \\
\hline CA (yr) & $8.4 \pm 0.6$ & $8.4 \pm 0.6$ & $8.4 \pm 0.6$ & 0.621 \\
\hline $\mathrm{BA}(\mathrm{yr})$ & $10.0 \pm 0.7$ & $10.0 \pm 0.7$ & $10.0 \pm 0.6$ & 0.935 \\
\hline $\mathrm{BA}-\mathrm{CA}(\mathrm{yr})$ & $1.6 \pm 0.7$ & $1.6 \pm 0.7$ & $1.6 \pm 0.5$ & 0.701 \\
\hline Height (cm) & $132.0 \pm 5.3$ & $132.0 \pm 5.2$ & $132.0 \pm 5.5$ & 0.954 \\
\hline Height SDS for CA & $0.8 \pm 0.8$ & $0.8 \pm 0.8$ & $0.8 \pm 0.8$ & 0.767 \\
\hline Height SDS for BA & $-1.2 \pm 0.8$ & $-1.2 \pm 0.8$ & $-1.3 \pm 0.8$ & 0.909 \\
\hline $\mathrm{PAH}(\mathrm{cm})$ & $158.5 \pm 6.0$ & $158.5 \pm 6.2$ & $158.5 \pm 5.3$ & 0.969 \\
\hline PAHSDS & $-0.5 \pm 1.2$ & $-0.5 \pm 1.3$ & $-0.5 \pm 1.1$ & 0.936 \\
\hline BMI $\left(\mathrm{kg} / \mathrm{m}^{2}\right)$ & $17.1 \pm 1.8$ & $17.2 \pm 1.8$ & $17.0 \pm 2.0$ & 0.676 \\
\hline BMI SDS for CA & $0.2 \pm 0.8$ & $0.2 \pm 0.8$ & $0.2 \pm 0.8$ & 0.612 \\
\hline BMI SDS for BA & $-0.6 \pm 0.7$ & $-0.5 \pm 0.7$ & $-0.6 \pm 0.7$ & 0.548 \\
\hline Midparental height (cm) & $159.8 \pm 5.1$ & $160.0 \pm 3.8$ & $159.5 \pm 7.3$ & 0.572 \\
\hline Midparental height SDS & $-0.2 \pm 1.1$ & $-0.2 \pm 0.8$ & $-0.3 \pm 1.7$ & 0.470 \\
\hline Small for gestational age & $9(6.0)$ & $4(3.8)$ & $5(11.1)$ & 0.084 \\
\hline Basal LH (IU/L) & $0.9 \pm 0.7$ & $1.0 \pm 0.7$ & $0.9 \pm 0.7$ & 0.578 \\
\hline Basal FSH (IU/L) & $2.2 \pm 1.3$ & $2.2 \pm 1.2$ & $2.3 \pm 1.4$ & 0.493 \\
\hline Peak LH (IU/L) & $10.9 \pm 7.0$ & $11.2 \pm 7.0$ & $10.3 \pm 7.0$ & 0.463 \\
\hline Peak FSH (IU/L) & $11.3 \pm 5.4$ & $11.5 \pm 5.4$ & $11.1 \pm 5.3$ & 0.698 \\
\hline Estradiol $(p g / m L)$ & $30.1 \pm 16.6$ & $31.5 \pm 17.7$ & $26.8 \pm 13.4$ & 0.110 \\
\hline Dose of GnRH agonist ( $\mu \mathrm{g} / \mathrm{kg} / \mathrm{mo})$ & $82.9 \pm 9.0$ & $84.9 \pm 8.2$ & $78.4 \pm 9.3$ & $<0.001$ \\
\hline Breast SMR (I/II/III/IV/V) & 0/94/55/1/0 & 0/76/28/1/0 & 0/18/27/0/0 & $<0.001$ \\
\hline
\end{tabular}

Values are presented as mean \pm standard deviation or number (\%).

Group 1, subjects treated with 1-month depot formulation for 1 year; group 2, subjects treated with 1-month depot formulation for 6 months and subsequently switch to 3-month depot formulation; CA, chronological age; BA, bone age; SDS, standard deviation score; $\mathrm{PAH}$, predicted adult height; BMI, body mass index; LH, luteinizing hormone; FSH, follicular stimulating hormone; GnRH, gonadotropinreleasing hormone; SMR, sexual maturity rate by Tanner stage. 
biochemically, but all patients showed $\mathrm{LH}$ level $<3$ IU/L at 1 year.

\section{Comparison between groups at 6 months and 1 year of GnRHa treatment}

After 6 and 12 months of GnRHa treatment, CA, BA, BACA difference, height SDS for BA and CA, BMI SDS for BA and $\mathrm{CA}, \mathrm{PAH}$, and PAH SDS did not differ significantly between groups (Table 2, Fig. 2). The LH level after GnRH stimulation in group 2 was significantly higher than that in group $1(1.1 \pm 0.4$ IU/L vs. $1.4 \pm 0.5 \mathrm{IU} / \mathrm{L}, P<0.001)$ after 12 months of treatment but was suppressed in all subjects. The dose of GnRHa $(\mu \mathrm{g} / \mathrm{kg} /$ mo) did not differ significantly between the groups after 6 or 12 months of GnRHa treatment. In both groups, breast SMR was suppressed (Table 2).

\section{Discussion}

Long-acting GnRHas have been the standard treatment for CPP since the mid-1980s. ${ }^{2)}$ In this study, we compared the efficacy of a 3-month depot formulation of GnRHa with that of a 1-month depot in girls with CPP. During the 6-month period of comparison between the 1-month and 3-month GnRHa treatments, we found no differences in anthropometric, radiographic, or laboratory parameters between groups. This indicates that the 3-month depot GnRHa formulation has short-term efficacy comparable to that of the 1-month depot. Although the LH level after GnRH stimulation was higher in group 2 than in group 1 at 12 months, LH level was sufficiently suppressed in all subjects in both groups.

In CPP patients, GnRHa administration suppresses pubertal progression by desensitizing and downregulating pituitary GnRH receptors. In this study, breast SMR was decreased after 6

Table 2. Comparison of clinical parameters between groups at 6 and 12 months by groups after gonadotropin-releasing hormone (GnRH) agonist treatment

\begin{tabular}{|c|c|c|c|c|c|}
\hline Variable & Group & Baseline & 6 Months & 12 Months & $P$-value \\
\hline \multirow[t]{2}{*}{ CA (yr) } & 1 & $8.4 \pm 0.6^{a, b}$ & $8.9 \pm 0.7^{\mathrm{a}, \mathrm{c}}$ & $9.4 \pm 0.7^{b, c}$ & $<0.001$ \\
\hline & 2 & $8.4 \pm 0.6^{a, b}$ & $8.9 \pm 0.6^{a, c}$ & $9.4 \pm 0.6^{b, c}$ & $<0.001$ \\
\hline \multirow[t]{2}{*}{$B A(y r)$} & 1 & $10.0 \pm 0.7^{\mathrm{a}, \mathrm{b}}$ & $10.4 \pm 0.7^{\mathrm{a}, \mathrm{c}}$ & $10.6 \pm 0.6^{b, c}$ & $<0.001$ \\
\hline & 2 & $10.0 \pm 0.6^{a, b}$ & $10.4 \pm 0.6^{\mathrm{a}, \mathrm{c}}$ & $10.7 \pm 0.5^{\mathrm{b}, \mathrm{c}}$ & $<0.001$ \\
\hline \multirow[t]{2}{*}{ BA-CA (yr) } & 1 & $1.6 \pm 0.7^{a, b}$ & $1.5 \pm 0.7^{\mathrm{a}, \mathrm{c}}$ & $1.2 \pm 0.7^{b, c}$ & $<0.001$ \\
\hline & 2 & $1.6 \pm 0.5^{a, b}$ & $1.5 \pm 0.6^{a, c}$ & $1.3 \pm 0.6^{b, c}$ & $<0.001$ \\
\hline \multirow[t]{2}{*}{ Height (cm) } & 1 & $132.0 \pm 5.2^{\mathrm{a}, \mathrm{b}}$ & $135.3 \pm 5.3^{\mathrm{a}, \mathrm{c}}$ & $137.8 \pm 5.3^{\mathrm{b}, \mathrm{c}}$ & $<0.001$ \\
\hline & 2 & $132.0 \pm 5.5^{a, b}$ & $135.5 \pm 5.4^{\mathrm{a}, \mathrm{c}}$ & $138.1 \pm 5.6^{b, c}$ & $<0.001$ \\
\hline \multirow[t]{2}{*}{ Height SDS for CA } & 1 & $0.8 \pm 0.8^{b}$ & $0.8 \pm 0.8^{c}$ & $0.7 \pm 0.8^{b, c}$ & $<0.001$ \\
\hline & 2 & $0.8 \pm 0.8$ & $0.9 \pm 0.8^{c}$ & $0.8 \pm 0.8^{c}$ & 0.020 \\
\hline \multirow[t]{2}{*}{ Height SDS for BA } & 1 & $-1.2 \pm 0.8^{\mathrm{a}, \mathrm{b}}$ & $-1.1 \pm 0.8^{a, c}$ & $-0.9 \pm 0.8^{b, c}$ & $<0.001$ \\
\hline & 2 & $-1.3 \pm 0.8^{a, b}$ & $-1.0 \pm 0.7^{\mathrm{a}, \mathrm{c}}$ & $-0.9 \pm 0.7^{b, c}$ & $<0.001$ \\
\hline \multirow[t]{2}{*}{ PAH (cm) } & 1 & $158.5 \pm 6.2^{a, b}$ & $159.2 \pm 6.0^{a, c}$ & $160.2 \pm 5.8^{b, c}$ & $<0.001$ \\
\hline & 2 & $158.5 \pm 5.3^{b}$ & $159.3 \pm 5.3$ & $159.8 \pm 5.0^{b}$ & 0.009 \\
\hline \multirow[t]{2}{*}{ PAH SDS } & 1 & $-0.5 \pm 1.3^{a, b}$ & $-0.3 \pm 1.2^{\mathrm{a}, \mathrm{c}}$ & $-0.1 \pm 1.2^{b, c}$ & $<0.001$ \\
\hline & 2 & $-0.5 \pm 1.1^{b}$ & $-0.3 \pm 1.1$ & $-0.2 \pm 1.0^{b}$ & 0.008 \\
\hline \multirow[t]{2}{*}{ BMI $\left(\mathrm{kg} / \mathrm{m}^{2}\right)$} & 1 & $17.2 \pm 1.8^{\mathrm{a}, \mathrm{b}}$ & $17.7 \pm 1.9^{\mathrm{a}, \mathrm{c}}$ & $18.3 \pm 2.0^{b, c}$ & $<0.001$ \\
\hline & 2 & $17.0 \pm 2.0^{\mathrm{a}, \mathrm{b}}$ & $17.7 \pm 2.0^{\mathrm{a}, \mathrm{c}}$ & $18.3 \pm 2.3^{b, c}$ & $<0.001$ \\
\hline \multirow[t]{2}{*}{ BMI SDS for CA } & 1 & $0.2 \pm 0.8^{a, b}$ & $0.3 \pm 0.8^{a, c}$ & $0.4 \pm 0.8^{b, c}$ & $<0.001$ \\
\hline & 2 & $0.2 \pm 0.8^{a, b}$ & $0.3 \pm 0.7^{\mathrm{a}}$ & $0.4 \pm 0.8^{b}$ & $<0.001$ \\
\hline \multirow[t]{2}{*}{ BMI SDS for BA } & 1 & $-0.5 \pm 0.7^{a, b}$ & $-0.4 \pm 0.8^{\mathrm{a}, \mathrm{c}}$ & $-0.3 \pm 0.7^{b, c}$ & $<0.001$ \\
\hline & 2 & $-0.6 \pm 0.7^{a, b}$ & $-0.4 \pm 0.7^{\mathrm{a}, \mathrm{c}}$ & $-0.3 \pm 0.8^{b, c}$ & $<0.001$ \\
\hline \multirow[t]{2}{*}{ LH after GnRH stimulation (IU/L) } & 1 & $11.2 \pm 7.0^{\mathrm{a}, \mathrm{b}}$ & $1.1 \pm 0.5^{\mathrm{a}}$ & $1.1 \pm 0.4^{b_{, * *}^{*}}$ & $<0.001$ \\
\hline & 2 & $10.3 \pm 7.0^{\mathrm{a}, \mathrm{b}}$ & $1.2 \pm 1.0^{\mathrm{a}}$ & $1.4 \pm 0.5^{\mathrm{b}_{*}^{* *}}$ & $<0.001$ \\
\hline \multirow[t]{2}{*}{ Dose of GnRH agonist ( $\mu \mathrm{g} / \mathrm{kg} / \mathrm{mo}$ ) } & 1 & $84.9 \pm 8.2^{a, b, b^{* *}}$ & $79.0 \pm 9.4^{\mathrm{a}, \mathrm{c}}$ & $72.2 \pm 11.9^{b, c}$ & $<0.001$ \\
\hline & 2 & $78.4 \pm 9.3^{b_{, * *}^{* *}}$ & $76.8 \pm 16.3^{c}$ & $70.7 \pm 14.4^{\mathrm{b}, \mathrm{c}}$ & $<0.001$ \\
\hline \multirow[t]{2}{*}{ Breast SMR, I: II : II : IV :V } & 1 & $0: 76: 28: 1: 0^{* *}$ & $97: 8: 0: 0: 0$ & $100: 5: 0: 0: 0$ & $<0.001$ \\
\hline & 2 & $0: 18: 27: 0: 0^{* *}$ & $43: 2: 0: 0$ & $43: 2: 0: 0$ & $<0.001$ \\
\hline
\end{tabular}

Values are presented as mean \pm standard deviation or number.

Group 1, subjects treated with 1-month depot formulation for 1 year; group 2, subjects treated with 1-month depot formulation for 6 months and subsequently switch to 3-month depot formulation; CA, chronological age; BA, bone age; SDS, standard deviation score; PAH, predicted adult height; BMI, body mass index; LH, luteinizing hormone; SMR, sexual maturity rate by Tanner stage.

Superscript $a, b$, and $c$ indicate $P<0.05$ between baseline and 6 month, between 0 and 12 months, and between 6 and 12 months, respectively.

${ }^{\dagger} P$-value from repeated measures analysis of variance of baseline, 6 months, and 12 months. ${ }^{* \prime \prime} P<0.01$, statistically significant differences between groups 1 and 2 . 

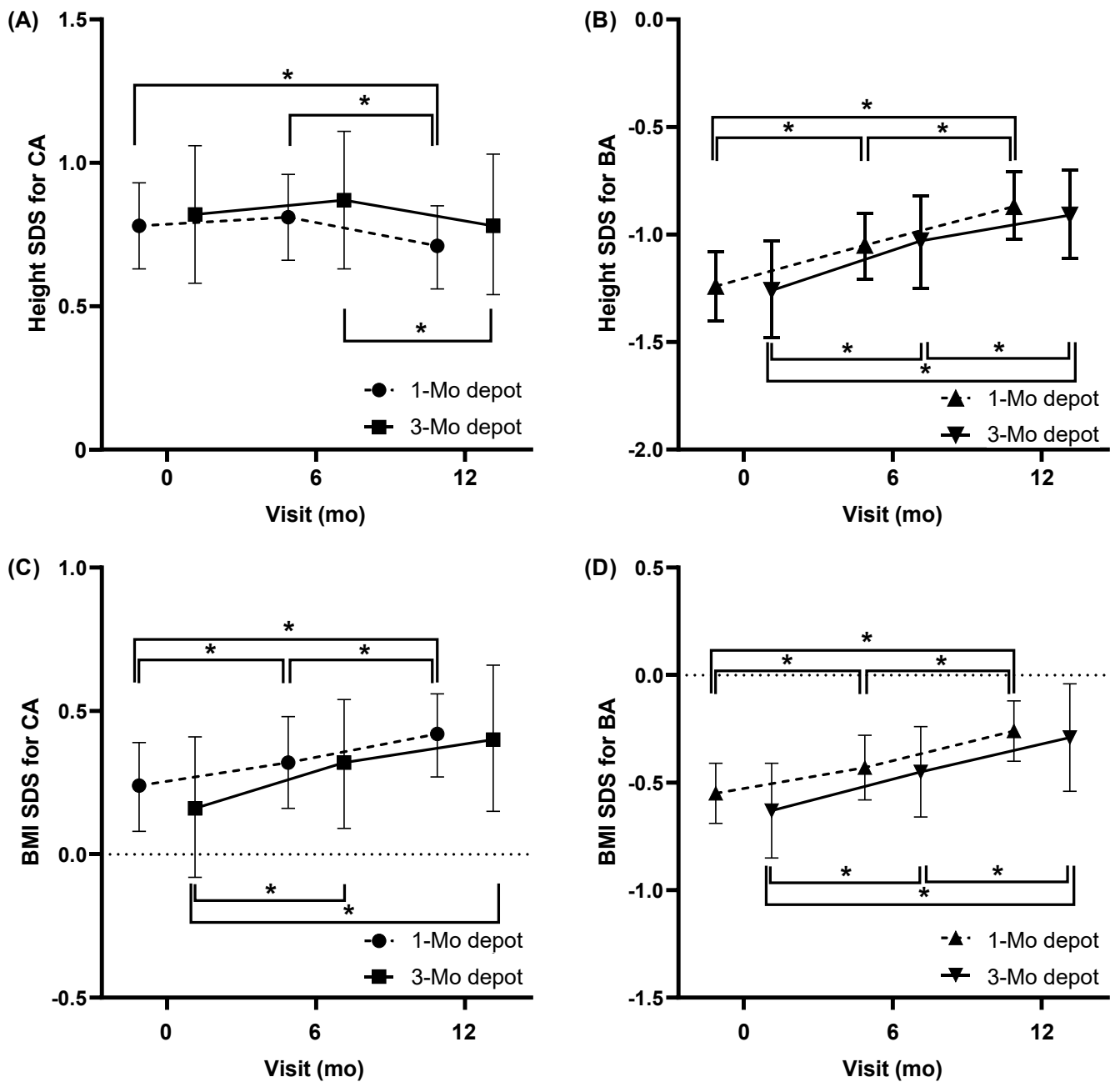

Fig. 2. Changes in height SDS for CA (A), height SDS for BA (B), BMI SDS for CA (C), and BMI SDS for BA (D) by group and visit. SDS, standard deviation score; $C A$, chronological age; $B A$, bone age.

and 12 months of GnRHa treatment in both groups. Moreover, GnRH-stimulated LH level showed sufficient suppression of pubertal development with both GnRHa formulations. Other studies of a 3-month depot formulation reported similar results. Carel et al. ${ }^{17)}$ observed that a 3 -month depot formulation of leuprolide acetate $(11.25 \mathrm{mg})$ effectively suppressed gonadotropin secretion. A 36-month study showed that a 3-month depot of leuprolide acetate effectively suppressed pubertal symptoms and signs without causing any new adverse effects. ${ }^{18)}$ A triptorelin $11.25 \mathrm{mg} 3$-month depot also effectively suppressed LH level. ${ }^{19)}$ In that study, the GnRHa dose ( $\mu \mathrm{g} / \mathrm{kg} /$ mo) decreased during the treatment period because of weight gain (Table 2). In this study, the GnRHa dose (mg/mo) had not changed when pubertal signs were sufficiently suppressed.

Several studies have shown that GnRHa treatment improves the final height of CPP patients. ${ }^{7,20)}$ Fuld et al. ${ }^{10)}$ reported that administering GnRHa using a 1-month $7.5 \mathrm{mg}$, 3-month $11.25 \mathrm{mg}$, or 3-month $22.5 \mathrm{mg}$ formulation showed effective suppression without causing any significant difference in height,
BA, or PAH among groups. Bertelloni et al. ${ }^{21)}$ showed similar adult heights between girls treated with monthly $(3.75 \mathrm{mg})$ or quarterly triptorelin $(11.25 \mathrm{mg})$. Our results are consistent with those of previous studies. The height SDS for BA and PAH increased during treatment in both groups. Furthermore, the $\mathrm{BA}-\mathrm{CA}$ difference decreased during treatment, indicating an attenuation of BA advancement with both GnRHa depots. Some studies showed that greater $\mathrm{LH}$ suppression increased $\mathrm{PAH}^{22,23)}$ In this study, after 12 months of treatment, the LH level was higher in the 3-month depot group than in the 1-month depot group, but PAH showed no significant difference $(160.2 \pm 5.8 \mathrm{~cm}$ for group 1 and $159.8 \pm 5.0 \mathrm{~cm}$ for group 2). Further long-term studies with leuprolide acetate are required to assess the final height.

There has been controversy about the association between GnRHa treatment and weight gain or obesity. ${ }^{24)}$ Several studies have shown increased BMI SDS during GnRHa treatment and decreased BMI SDS after discontinuation of GnRHa. ${ }^{25-28)}$ In a study with a 1-month GnRHa depot formulation, the 
proportion of normal weight, overweight, and obese subjects did not differ significantly before and after discontinuation of GnRHa treatment. ${ }^{28)}$ An increase in BMI SDS during GnRHa treatment might reflect relatively more weight gain than height gain because of pubertal suppression by GnRHa. In this study, GnRHa treatment significantly increased BMI and BMI SDS in both groups during 1 year of GnRHa treatment, which is in concordance with previous studies. ${ }^{26,28)}$ However, the type of GnRHa made no significant difference in the BMI SDS change. Additional long-term follow-up is required.

The doses of GnRHa administered to treat CPP vary worldwide. In the United States, the recommended starting doses for 1-month and 3-month depot leuprolide preparations range from $7.5 \mathrm{mg}$ to $15 \mathrm{mg}$ and $11.25 \mathrm{mg}$ to $30 \mathrm{mg}$, respectively. ${ }^{29)} \mathrm{On}$ the contrary, Europe and Asia have established a lower standard dose of $3.75 \mathrm{mg}^{30,31)}$ Although the dose of GnRHa in CPP patients in Korea and Asia is lower than that in other countries, low-dose GnRHa treatment efficiently suppressed the pituitarygonadal axis, and PAH was not different from those treated with a higher dose. ${ }^{32,33)}$ After 12 months of GnRHa treatment in both groups, pubertal symptoms had regressed and stabilized, and LH level was suppressed.

Our study has several limitations. First, this was a retrospective, single-center study with a relatively short duration. Second, we did not evaluate adverse events with either the 1-month or 3 -month depot. However, all subjects in both groups tolerated each GnRHa formulation well and continued to use it for at least 12 months. Despite its limitations, this study is the first to compare the efficacy of 1-month and 3-month depot formulations of GnRHa in Korean patients with CPP.

In conclusion, the 3-month depot formulation of GnRHa effectively suppressed the pituitary-gonadal axis and gonadotropin secretion in girls with CPP. Treatment with a 3-month GnRHa depot was comparable to that with a 1-month depot in terms of successful inhibition of pubertal progression, attenuation of BA advancement, and increased PAH after a safe switch from the monthly formulation. Because it offers improved convenience and compliance, a 3-month depot formulation could be a viable option for treatment of CPP. Further long-term prospective studies are required to confirm our results and investigate treatment safety.

\section{Ethical statement}

This study was approved by the Seoul National University Bundang Hospital Institutional Review Board (IRB) (IRB number: B-2005-613-113), and the requirement for informed consent was waived by the IRB.

\section{Conflict of interest}

JHK received an honorarium from Takeda, Ferring, and Ipsen. No other potential conflicts of interest relevant to this article are reported.

\section{References}

1. Parent AS, Teilmann G, Juul A, Skakkebaek NE, Toppari J, Bourguignon JP. The timing of normal puberty and the age limits of sexual precocity: variations around the world, secular trends, and changes after migration. Endocr Rev 2003;24:668-93.

2. Latronico AC, Brito VN, Carel JC. Causes, diagnosis, and treatment of central precocious puberty. Lancet Diabetes Endocrinol 2016;4:265-74.

3. Carel JC, Eugster EA, Rogol A, Ghizzoni L, Palmert MR, Group E-LGACC, et al. Consensus statement on the use of gonadotropin-releasing hormone analogs in children. Pediatrics 2009; 123:e752-62.

4. Parker KL, Lee PA. Depot leuprolide acetate for treatment of precocious puberty. J Clin Endocrinol Metab 1989;69:689-91.

5. Mul D, Hughes IA. The use of GnRH agonists in precocious puberty. Eur J Endocrinol 2008;159 Suppl 1:S3-8.

6. Partsch CJ, Heger S, Sippell WG. Management and outcome of central precocious puberty. Clin Endocrinol (Oxf) 2002;56:129-48.

7. Bertelloni S, Baroncelli GI, Ferdeghini M, MenchiniFabris F, Saggese G. Final height, gonadal function and bone mineral density of adolescent males with central precocious puberty after therapy with gonadotropinreleasing hormone analogues. Eur J Pediatr 2000;159:36974.

8. Badaru A, Wilson DM, Bachrach LK, Fechner P, Gandrud LM, Durham E, et al. Sequential comparisons of onemonth and three-month depot leuprolide regimens in central precocious puberty. J Clin Endocrinol Metab 2006;91:1862-7.

9. Isaac H, Patel L, Meyer S, Hall CM, Cusick C, Price DA, et al. Efficacy of a monthly compared to 3-monthly depot GnRH analogue (goserelin) in the treatment of children with central precocious puberty. Horm Res 2007;68:157-63.

10. Fuld K, Chi C, Neely EK. A randomized trial of 1- and 3-month depot leuprolide doses in the treatment of central precocious puberty. J Pediatr 2011;159:982-7.e1.

11. Lee PA, Klein K, Mauras N, Neely EK, Bloch CA, Larsen L, et al. Efficacy and safety of leuprolide acetate 3-month depot 11.25 milligrams or 30 milligrams for the treatment of central precocious puberty. J Clin Endocr Metab 2012;97:1572-80.

12. Kim JH, Yun S, Hwang SS, Shim JO, Chae HW, Lee YJ, et al. The 2017 Korean National Growth Charts for children and adolescents: development, improvement, and prospects. Korean J Pediatr 2018;61:135-49.

13. Greulich WW, Pyle SI. Radiologic atlas of skeletal development of the hand and wrist. 2nd ed. Redwood City (CA): Stanford University Press, 1959.

14. Marshall WA, Tanner JM. Variations in pattern of pubertal changes in girls. Arch Dis Child 1969;44:291-303. 
15. Bayley N, Pinneau SR. Tables for predicting adult height from skeletal age: revised for use with the Greulich-Pyle hand standards. J Pediatr 1952;40:423-41.

16. Kim YJ, Lee HS, Lee YJ, Lim JS, Kim SY, Kim EY, et al. Multicenter clinical trial of leuprolide acetate depot (Luphere depot $3.75 \mathrm{mg}$ ) for efficacy and safety in girls with central precocious puberty. Ann Pediatr Endocrinol Metab 2013; 18:173-8.

17. Carel JC, Lahlou N, Jaramillo O, Montauban V, Teinturier C, Colle M, et al. Treatment of central precocious puberty by subcutaneous injections of leuprorelin 3-month depot (11.25 mg). J Clin Endocrinol Metab 2002;87:4111-6.

18. Lee PA, Klein K, Mauras N, Lev-Vaisler T, Bacher P. 36-month treatment experience of two doses of leuprolide acetate 3-month depot for children with central precocious puberty. J Clin Endocrinol Metab 2014;99:3153-9.

19. Durand A, Tauber M, Patel B, Dutailly P. Meta-analysis of paediatric patients with central precocious puberty treated with intramuscular triptorelin $11.25 \mathrm{mg} 3$-month prolonged-release formulation. Horm Res Paediatr 2017;87:224-32.

20. Bertelloni S, Baroncelli GI, Sorrentino MC, Perri G, Saggese G. Effect of central precocious puberty and gonadotropinreleasing hormone analogue treatment on peak bone mass and final height in females. Eur J Pediatr 1998;157:363-7.

21. Bertelloni S, Massart F, Einaudi S, Wasniewska M, Miccoli M, Baroncelli GI. Central precocious puberty: adult height in girls treated with quarterly or monthly gonadotropinreleasing hormone analog triptorelin. Horm Res Paediatr 2015;84:396-400.

22. Kunz GJ, Sherman TI, Klein KO. Luteinizing hormone (LH) and estradiol suppression and growth in girls with central precocious puberty: is more suppression better? Are pre-injection LH levels useful in monitoring treatment? J Pediatr Endocrinol Metab 2007;20:1189-98.

23. Lanes R, Soros A, Jakubowicz S. Accelerated versus slowly progressive forms of puberty in girls with precocious and early puberty. Gonadotropin suppressive effect and final height obtained with two different analogs. J Pediatr Endocrinol Metab 2004;17:759-66.

24. Traggiai C, Perucchin PP, Zerbini K, Gastaldi R, De Biasio P, Lorini R. Outcome after depot gonadotrophin- releasing hormone agonist treatment for central precocious puberty: effects on body mass index and final height. Eur J Endocrinol 2005; 153:463-4.

25. Vuralli D, Ozon ZA, Gonc EN, Alikasifoglu A, Kandemir N. Long-term effects of GnRH agonist treatment on body mass index in girls with idiopathic central precocious puberty. J Pediatr Endocrinol Metab 2020;33:99-105.

26. Censani M, Feuer A, Orton S, Askin G, Vogiatzi M. Changes in body mass index in children on gonadotropin-releasing hormone agonist therapy with precocious puberty, early puberty or short stature. J Pediatr Endocrinol Metab 2019;32:1065-70.

27. Paterson WF, McNeill E, Young D, Donaldson MDC. Auxological outcome and time to menarche following longacting goserelin therapy in girls with central precocious or early puberty. Clin Endocrinol 2004;61:626-34.

28. Yoon JW, Park HA, Lee J, Kim JH. The influence of gonadotropin-releasing hormone agonists on anthropometric change in girls with central precocious puberty. Korean J Pediatr 2017;60:395-402.

29. Bangalore Krishna K, Fuqua JS, Rogol AD, Klein KO, Popovic J, Houk CP, et al. Use of gonadotropin-releasing hormone analogs in children: update by an international consortium. Horm Res Paediatr 2019;91:357-72.

30. Tanaka T, Niimi H, Matsuo N, Fujieda K, Tachibana K, Ohyama K, et al. Results of long-term follow-up after treatment of central precocious puberty with leuprorelin acetate: evaluation of effectiveness of treatment and recovery of gonadal function. The TAP-144-SR Japanese Study Group on Central Precocious Puberty. J Clin Endocrinol Metab 2005;90:1371-6.

31. Carel JC, Lahlou N, Guazzarotti L, Joubert-Collin M, Roger M, Colle M, et al. Treatment of central precocious puberty with depot leuprorelin. French Leuprorelin Trial Group. Eur J Endocrinol 1995;132:699-704.

32. Choi JH. Proper dosage and duration of GnRH agonist treatment in central precocious puberty. J Korean Soc Pediatr Endocrinol 2006;11:8-14.

33. Jin HY, Choi JH, Yoo HW. Evaluation of efficacy of GnRH agonist on predicted adult height $(\mathrm{PAH})$ in patients with central precocious puberty using two different dosages. J Korean Soc Pediatr Endocrinol 2010;15:120-5. 